DOI: https://doi.org/10.47405/mjssh.v5i10.505

\begin{tabular}{|c|c|}
\hline 7 & Malaysian Journal of Social Sciences and Humanities (MJSSH) \\
\hline Malaysian Journal of & Volume 5, Issue 10 , October 2020 \\
\hline $\begin{array}{l}\text { Humantites } \\
\text { (MJ - SsH) }\end{array}$ & e-ISSN : 2504-8562 \\
\hline & $\begin{array}{l}\text { Journal home page: } \\
\text { www.msocialsciences.com }\end{array}$ \\
\hline
\end{tabular}

\title{
Kempen Penghayatan Bulan kebangsaan Wahana Menyampaikan Mesej
}

\author{
Sitinurbayu Mohd Yusoff ${ }^{1}$, Syahruddin Ag Ahmad ${ }^{1}$, Aisah Meri ${ }^{1}$, Cyril Modili ${ }^{1}$, Eko Prayitno Joko ${ }^{1}$ \\ 1Fakulti Sains Sosial dan Kemanusiaan, Universiti Malaysia Sabah (UMS)
}

Correspondence: Sitinurbayu Mohd Yusoff (bayu.yusoff@ums.edu.my)

\begin{abstract}
Abstrak
Kempen merupakan satu set aktiviti yang dirancang oleh seseorang dalam jangka masa tertentu untuk mencapai sesuatu objektif. Dalam mencapai misi dan matlamat, setiap kempen berbeza dari segi pendekatannya bergantung kepada objektif dan khalayak sasaran. Matlamat utama kempen kesedaran awam bertujuan untuk memberi kesedaran kepada masyarakat mengenai sesuatu dasar, perkhidmatan, program atau mengenai sesuatu isu. Oleh itu, kerajaan bertanggungjawab merancang dan melaksanakan kempen Hari Kebangsaan dengan teliti bagi mencapai tujuan yang direncanakan agar dapat dihayati dengan sepenuh hati oleh golongan sasar. Dalam usaha mendidik dan meningkatkan kesedaran masyarakat terhadap kepentingan bulan Kebangsaan, setiap tahun kerajaan akan menganjurkan kempen Hari Kebangsaan bagi menyuntik semangat patriotisme di kalangan masyarakat. Oleh itu, wacana tentang kemerdekaan yang diketengahkan oleh pihak kerajaan melalui kempen bulan Kebangsaan saban tahun harus dirancang dengan teliti agar kewibawaan, konsep dan motif yang direncanakan dalam sesebuah kempen dapat dihayati dengan sepenuh hati oleh golongan sasar. Dalam masa yang sama kandungan serta tujuan kempen tersebut dijalankan agar dapat menjawab persoalan tentang kelunturan semangat patriotisme dalam kalangan belia hari ini. Perbincangan kumpulan fokus ke atas belia Sabah, Sarawak dan Semenanjung dijalankan khusus untuk mendapatkan maklumat tentang penghayatan mesej patriotisme menerusi kempen Hari Kebangsaan yang berpotensi membantu membina negara yang berdaya tahan dalam menghadapi cabaran dan arus pemodenan.
\end{abstract}

Kata kunci: kempen, Hari Kebangsaan, semantik, wacana, patriotisme

\section{National Day Campaign as a Medium to Convey Messages}

\begin{abstract}
A campaign is a set of activities planned by a person within a certain period of time to achieve an objective. Each campaign differs in terms of its approach depending on the objectives and target audience to achieve the mission and goals. The main goal of a public awareness campaign is to provide awareness to the public about a policy, service, program or on an issue. Therefore, the government is responsible for planning and implementing the National Day campaign carefully to achieve the planned goals so that it can be fully appreciated by the target group. Every year the government will organize a National Day campaign to inject the spirit of patriotism among the community in an effort to educate and raise public awareness on the importance of National Day. Therefore, the discourse on independence presented by the government through the National Day campaign every year should be carefully planned so that the authority, concepts and motives planned in a campaign can be fully appreciated by the target group. At the same time, the content and purpose of the campaign is carried
\end{abstract}


out in order to answer the question of the fading spirit of patriotism among the youth today. Group discussions focused on the youth of Sabah, Sarawak and the Peninsula were conducted specifically to obtain information on the message of patriotism through a potential National Day campaign in building a resilient nation in the face of the challenges and currents of modernization.

Keywords: campaign, National Day, semantics, discourse, patriotism

\section{Pengenalan}

Media dan komunikasi dikenalpasti boleh digunakan sebagai satu medium yang berkesan dalam penyebaran maklumat (Mohamad Hafifi Jamri et al, 2017). Apabila kerajaan perlu mempromosikan agenda mereka, strategi yang paling berkesan adalah dengan mempengaruhi minda masyarakat melalui media. Media dikenalpasti sebagai alat penyebaran ideologi kelas dominan. Golongan yang memerintah akan menguasai media dan menggunakan saluran media untuk menyebarkan ideologi mereka kepada masyarakat. Oleh sebab itu, kerajaan telah menganjurkan pelbagai aktiviti dan kempen sempena bulan Kebangsaan saban tahun. Antara mekanisme kempen Hari Kebangsaan adalah Kempen Kibar Jalur Gemilang, Pertandingan Mencipta Logo Hari Kebangsaan, Kembara Merdeka, Pertandingan Keceriaan Bulan Kebangsaan dan kandungan kempen oleh media massa seperti iklan, lagu patriotik dan sebagainya.

Kempen merupakan sebahagian dari alat komunikasi dalam pemasaran. Membangunkan strategi dalam komunikasi bukanlah sesuatu yang mudah sementelah ia direka untuk mempengaruhi tingkahlaku golongan sasar. Strategi komunikasi yang baik akan merangkumi tujuan dan objektif kempen diadakan, khalayak sasaran yang telah dikenalpasti, mesej yang dibangunkan serta nada secara keseluruhannya. Sesuatu kempen seharusnya mengambilkira kesemua keputusan strategik yang dibuat mengenai komunikasi. Kewujudan kempen penghayatan semangat patriotisme sempena Hari Kebangsaan dijangka memberikan impak yang besar dalam mewujudkan semangat patriotisme di kalangan masyarakat.

Membina masyarakat belia yang mempunyai idealisme perjuangan dalam gelombang arus perubahan kebendaan yang berlaku sekarang merupakan satu cabaran yang amat besar. Ketandusan dan kelunturan semangat patriotik belia pada masa ini telah banyak diperkatakan atas keprihatinan yang menyentuh isu kesinambungan perjuangan generasi masa depan (Abd. Rahim, 2004). Justeru, kempen Hari Kebangsaan perlu berfungsi sebagai mekanisme komunikasi dalam menyampaikan mesej yang jelas dan jitu tentang masyarakat dan negara pada waktu sambutan Hari Kebangsaan tersebut. Hal yang demikian dapat membantu kerajaan membibitkan aspirasi bagi memajukan negara menerusi semangat patriotisme dalam kalangan masyarakat.

Terhakisnya semangat patriotik dalam kalangan belia mendorong pihak kerajaan untuk menggiatkan usaha ke arah menimbul dan mengekalkan kesedaran terhadap semangat tersebut. Ini terbukti pada tahun 2019, kerajaan berusaha untuk meningkatkan kesedaran dalam kalangan masyarakat terhadapat semangat patriotisme menerusi Kempen Kibar Jalur Gemilang. Menteri Komunikasi dan Multimedia (2019), Gobind Singh Deo berkata bahawa kempen berkenaan masih kurang mendapat sambutan dalam kalangan masyarakat, bagaimanapun kerajaan bertekad untuk mempergiatkan kempen itu khususnya di peringkat akar umbi agar Jalur Gemilang dapat berkibar dengan megah di sekolahsekolah, di pejabat kerajaan mahupun agensi swasta, di kedai-kedai, di kampung-kampung juga di bandar-bandar besar. Sementelah, Jalur Gemilang merupakan lambang kedaulatan negara.

Sambutan perayaan Hari Kebangsaan dianjurkan dengan harapan ia dapat membina jiwa kenegaraan yang tinggi dalam kalangan masyarakatnya yang majmuk. Sebarang bentuk konflik cuba dielakkan supaya wujud persefahaman dalam toleransi beragama agar setiap warga merasakan mereka memainkan peranan menyumbang dalam pembangunan negara. Ini berikutan sambutan dan kemeriahan Hari Kebangsaan dalam kalangan masyarakat didapati masih rendah, malahan berada pada tahap yang mendukacitakan seolah-olah menunjukkan bahawa semangat patriotisme semakin pudar 
dan sikap ingin berkorban demi negara sudah tiada dalam jiwa generasi kini (Noor Mohamad, 2012; Iskandar, 2017). Oleh itu, wacana tentang Kemerdekaan yang diketengahkan oleh pihak kerajaan melalui kempen bulan Kebangsaan saban tahun memungkinkan perkaitan tahap kesedaran belia terhadap pembentukan semangat patriotisme dalam diri. Peranan kempen dalam mengkomunikasikan mesej dari kerajaan diterokai dan dikenalpasti.

\section{Kepentingan Kajian}

Kajian ini bertujuan untuk mentafsir mesej tersirat tentang patriotisme yang disampaikan menerusi kempen Hari Kebangsaan dan seterusnya mengupas elemen yang mendorong pemupukan semangat patriotisme dalam diri belia di Malaysia. Sementelah generasi hari ini dikatakan sudah berani mencabar undang-undang, menghina para pemimpin, mempertikai dan mempersoalkan kontrak sosial dan apa yang terkandung dalam Perlembagaan, tidak menghormati agama dan bangsa lain, serta sanggup membakar dan menukar Jalur Gemilang merosakkan (Noor Mohamad Shakeel Hamid, 2015). Kejadian seumpama ini cuba dielakkan daripada terus berleluasa dan menjadi sebati dalam diri generasi muda di negara ini. Justeru, adalah wajar satu kajian dijalankan ke atas kempen Hari Kebangsaan dalam usaha kerajaan memupuk semangat patriotisme agar implikasi proses menggarap mesej dan penyebaran maksud tersirat di kalangan masyarakat di Malaysia dpt diteliti dan dirumuskan.

Kesedaran terhadap aspirasi kerajaan dalam kalangan rakyat lahir daripada kemahuan individu dan kumpulan komuniti dalam sesebuah negara untuk memberikan sumbangan kepada negara. Anak-anak muda kini rata-ratanya kabur sejarah serta gagal menghayati Kemerdekaan sebagai wadah perjuangan bangsa suatu ketika dahulu (Khoo Kay Kim, 2002). Belia merupakan golongan yang menjadi pelapis kepada kepimpinan sesebuah negara. Kelestarian kepimpinan yang baik adalah prasyarat kepada semangat mencintai negara terutama melalui acara sambutan Hari Kebangsaan tahunan di negara ini. Walau bagaimanapun timbul persoalan samada wujud atau tidak kesedaran dalam kalangan individu dan kumpulan belia terhadap pentingnya memiliki semangat patriotisme yang cuba ditanamkan menerusi kempen Hari Kebangsaan.

\section{Kempen Hari Kebangsaan dan Semangat Patriotisme Belia}

Penghayatan erti Kemerdekaan tidak terletak pada logo dan tema sahaja tetapi sebenarnya kempen penghayatan semangat patriotisme sempena Hari Kebangsaan juga merupakan salah satu mekanisme penting dalam menyambut peristiwa yang bersejarah ini. Pelbagai cara dilakukan dalam proses menerapkan, menyubur dan menyemarakkan semangat patriotisme di kalangan generasi muda masa kini. Selain menerusi pendidikan di sekolah, kempen Hari Kebangsaan dan lagu patriotik juga boleh digunakan sebagai medium untuk menyampaikan mesej tentang patriotisme kepada belia seluruh Malaysia. Pelbagai acara telah diadakan diseluruh negara untuk menyambut Hari Kebangsaan dengan penduduk pelbagai kaum bersama-sama mengambil bahagian dalam pelbagai aktiviti yang dianjurkan. Program sempena Hari Kebangsaan dilihat antara penyatuan masyarakat pelbagai bangsa, agama dan peringkat umur demi menghayati suasana ketika laungan kemerdekaan dilontarkan.

Setiap tahun, kerajaan telah memperuntukan beberapa juta ringgit bagi menyemarakkan sambutan Hari Kebangsaan di seluruh negara. Menerusi kempen Hari Kebangsaan, pelbagai aktiviti dirancang dilaksanakan di setiap daerah semua negeri. Setiap daerah dijangka melaksanakan pelbagai program dengan kerjasama pelbagai pihak termasuk pihak swasta. Pengisian kemerdekaan yang selaras dengan budaya dan masyarakat negara ini diharap dapat memupuk semangat patriotisme dan cintakan negara dalam diri semua rakyat Malaysia. Antara aktiviti-aktiviti yang dilaksanakan ialah pemasangan bendera, Bicara Tokoh, penyampaian Jalur Gemilang, Ambang Merdeka, Tayangan Layar Bestari dan aktiviti rekreasi. Melalui program sebegini semangat patriotik dalam kalangan masyarakat boleh diterapkan di samping memeriahkan lagi sambutan bulan Kebangsaan pada setiap tahun.

Semangat patriotisme penting dalam membentuk kestabilan dan kemakmuran negara terutamanya dalam era globalisasi ini. Belia perlu mempunyai semangat juang yang tinggi dan tidak mudah 
berputus asa apabila mendepani cabaran. Belia seharusnya sentiasa bersikap positif, kental dan terus bersemangat apabila ditimpa dugaan dalam usaha mempertahankan negara. Sikap patriotisme perlu wujud dalam diri mereka agar mampu menjadi seorang pejuang bangsa yang disegani dan dihormati. Justeru, wacana tentang Kemerdekaan yang diangkat oleh kempen dalam sambutan Hari Kebangsaan perlu dikaji agar kesedaran belia terhadap semangat patriotisme dapat dikenalpasti wujud atau tidak kesan daripada kempen tersebut.

Perlu diingatkan bahawa patriotisme dalam konteks Malaysia bukan sekadar tindakan mengibarkan Jalur Gemilang sewaktu sambutan Hari Kebangsaan, bukan juga sekadar menghafal dan menyanyikan lagu Negaraku, berikrar tentang Rukun Negara atau mengenal erti gagasan 1 Malaysia. Patriotisme adalah lebih dari itu dan ia merupakan satu mekanisme yang mengukuhkan lagi ketahanan nasional dan meletakkan Malaysia sebagai sebuah negara berdaya saing di dunia.

Menurut Tatiana (2015), patriotisme merujuk kepada perasaan sayang kepada tanahair sendiri dan kebaktian kepada keluarga atau puak sendiri. Hal tersebut menunjukkan bahawa patriotisme itu merupakan satu emosi dalaman yang wujud dalam diri setiap warganegara yang berintegriti dan beretika. Beliau menjelaskan lagi bahawa kefahaman definisi patriotisme adalah sangat berbeza bagi individu dan kumpulan. Terdapat patriotisme dalam kalangan rakyat yang berunsur agama dan yang bersifat sekular. Malahan ada juga patriotisme yang berlandaskan aliran politik, berunsur budaya dan juga merupakan kebaktian kepada cara kehidupan sahaja. Penafsiran definisi tersebut menurut Tatiana (2015) adalah bergantung kepada pandangan masing-masing.

Wan Mohd. Nor (2015) dalam kajian serupa menyatakan bahawa sebagai sebuah negara yang sederhana besar, masih belum lama merdeka secara politik, dan sedang membangun dalam pelbagai segi utama kehidupan berbilang bangsa dan agama, Malaysia sedang menghadapi cabaran-cabaran luar hasil dari gelombang besar globaliasi. Justeru, menurut beliau lagi kegagalan menghadapi gelombang besar globalisasi boleh mengakibatkan kehilangan Kemerdekaan ekonomi dan politik terutama oleh negara-negara sedang membangun. Maka dengan itu, penjajahan baharu yang tidak semestinya bersifat ketenteraan boleh berlaku dengan berkesan pada bila-bila masa. Sebab itulah sesebuah kerajaan secara sedar perlu berusaha dalam memastikan negaranya dan tindakan sedemikian harus digerakkan lebih bersungguh-sungguh menyemai dan menyemarakkan semangat kebangsaan dan patriotisme di kalangan setiap lapisan masyarakat, bermula dari peringkat sekolah rendah lagi.

Kajian yang dilakukan oleh Eko Prayitno, Zaini dan Saat (2016), menjelaskan bahawa peranan golongan muda memperlihatkan perbezaan bagi setiap angkatan yang diperjuangkan mereka. Hal tersebut menjelaskan bahawa sasaran perjuangan golongan muda sebelum merdeka adalah untuk melahirkan benih-benih nasionalisme dan mengembangkan idealisme penyatuan bangsa agar dapat menendang keluar penjajah British daripada tanah air tercinta. Di sebalik perubahan sosial yang dinamik berlaku dalam masyarakat, peranan golongan belia tenggelam dalam arus kemajuan dan perubahan teknologi masakini.

Azwani et al, (2014) menjelaskan bahawa patriotisme adalah bersifat spiritual iaitu rasa kecintaan yang mendalam, subur dan kental kepada negara yang turut dicirikan oleh beberapa nilai seperti kesungguhan, keyakinan, keberanian dan kesinambungan. Ciri-ciri kognitif dan afektif yang membentuk kecintaan kepada negara ini haruslah diasuh dan disematkan dalam diri warganegara khusus untuk membina jiwa dan jasad rakyat yang utuh sebagai rakyat Malaysia yang menyayangi sekaligus mempunyai rasa memiliki Malaysia sebagai tanah tumpah darahnya. Justeru, penerapan, penyuburan dan penyemarakan patriotisme Malaysia adalah bukan untuk menyiapkan bangsa Malaysia bertempur di medan perang, tetapi untuk menjadikan bangsa Malaysia bersedia untuk berjuang, berkorban dan bertempur di seluruh medan kehidupan, termasuk bidang kritikal seperti keilmuan, keagamaan, ekonomi, perdagangan, siasah dan diplomasi antarabangsa.

Kegagalan generasi muda yang dibesarkan selepas zaman merdeka untuk mempamerkan semangat perjuangan mereka untuk mencapai wawasan dikesan berpunca daripada kurangnya sokongan dan dorongan patriotisme. Sebilangan belia yang luntur semangat idealismenya terhadap perjuangan dan kehidupan terus terjerumus dalam kancah keruntuhan moral. Justeru, jika agenda perjuangan diri dan 
agenda perjuangan bangsa tidak dapat dilanjutkan oleh belia yang menjadi barisan belakang kepada perjuangan bangsa, sudah tentu ini amat mengecewakan matlamat untuk membina bangsa yang bermaruah dan berwibawa. Sikap tidak patriotik telah menjadikan belia tidak berwawasan untuk memahami secara kritikal isu dan permasalahan negara yang memerlukan pelapis untuk menjadi pemimpin negara (Abd. Rahim, 2004).

\section{Dapatan Kajian}

Perbincangan kumpulan fokus telah dijalankan untuk melihat pandangan dan persepsi khalayak mengenai fungsi dan kepentingan kempen dalam sambutan Hari Kebangsaan. Dapatan yang digarap daripada perbincangan kumpulan fokus dikaitkan dengan konsep patriotisme sebagai pemangkin kepada kesedaran terhadap semangat tersebut dalam kalangan rakyat negara ini khususnya golongan media. Dapatan kajian yang diperolehi adalah berdasarkan dua (2) soalan penting yang dikemukakan menerusi perbincangan kumpulan fokus yang telah dijalankan. Soalan-soalan tersebut diberi tumpuan berbanding dengan soalan-soalan yang lain kerana penyelidik merasakan soalan-soalan tersebut lebih relevan dengan konteks kempen yang ingin dikaji iaitu mengenai tahap kesedaran semangat patriotisme dalam diri masyarakat Malaysia menerusi mekanisme kempen penghayatan Hari Kebangsaan serta mesej dalam kempen tersebut. Didapati terdapat beberapa perspektif menarik yang dapat dirumuskan menerusi kaedah perbincangan kumpulan fokus yang telah dijalankan.

\section{Kempen dan Semangat Patriotisme}

Menurut Azwani et al, (2014), tahap semangat patriotisme mungkin berbeza antara setiap generasi berdasarkan pengalaman berlainan yang dilalui. Walaupun pada hakikatnya ia tetap berpaksi pada makna yang sama, iaitu cintakan tanahair yang jitu. Hal tersebut adalah kerana, bagi generasi yang hidup pada zaman penjajah, fokus patriotismenya adalah untuk membebaskan diri daripada penjajahan dan memperjuangkan Kemerdekaan, tetapi bagi generasi selepas Merdeka, perjuangan untuk mengisi Kemerdekaan itu sendiri lebih menjadi keutamaan. Apabila responden ditanya mengenai pendapat mereka tentang kepentingan kempen Hari Kebangsaan dalam memupuk semangat patriotisme dalam diri individu dan kumpulan belia, mereka memberikan persepsi yang pelbagai.

Terdapat responden yang menyokong kempen yang dianjurkan oleh kerajaan dan mengakui kewujudan semangat patriotisme dalam diri mereka disebabkan oleh kempen-kempen tersebut.

Responden 7 Bagi saya, patriotisme merupakan perasaan cintakan negara. Itu paling utama. Ekspresi, cara tunjukkan kecintaan kita terhadap negara adalah dengan cara kibar bendera (kempen) dan sebagainya...

Ada informan yang menyatakan bahawa penglibatan dalam aktiviti atau kempen Hari Kebangsaan anjuran kerajaan boleh mendorong kewujudan semangat patriotisme dalam diri masyarakat. Penyertaan masyarakat dalam mana-mana kempen Hari Kebangsaan yang dianjurkan oleh kerajaan boleh membangkitkan emosi yang bersifat patriotik serta dapat menzahirkan rasa kecintaan terhadap negara. Justeru, pengekalan penganjuran pelbagai aktiviti dalam kempen penghayatan bulan Kebangsaan oleh kerajaan dilihat boleh mendorong masyarakat untuk sama-sama mengambil bahagian dalam menjayakan kempen tersebut.

Responden 6: $\quad$ Kempen-kempen yang diorang (kerajaan) buat ni... termasuk dengan apa-apa aktiviti-aktiviti... pertandingan lain tu semua... memang ada la jugak beri semangat patriotik dalam.... dalam masyarakat ni... secara tersirat la ... kita tak nampak... aaa... org kata participation tu... aaa... bila ... satu pertandingan tu melibatkan... aaa ... kita... contohnya... bila kita masuk pertandingan tu... aaa ... baru semangat tu datang... compare dengan kalau kita tengok iklan kt tv je... kita tengok iklan 
DOI: https://doi.org/10.47405/mjssh.v5i10.505

dalam tv kita just tengok je... dia tak menusuk la ... orang kata dalam hati kita... Maknanya... apa-apa pertandingan yang melibatkan ... aaa ... penyertaan ... kita masuk... involve sekali baru kita rasa... orang yang pergi perarakan... dia jalan sekali... join sekali perararakan tu ... aaa ... dia rasa ... dia laungkan Merdeka... Merdeka... kita pun uiii bestnya... atau pun bila lagu negaraku dipasang dia berdiri tegak,... dia nyanyi sekali... rasa... kita tengok kt tv kita duduk sambal makan popcorn ... kita tengok je... kita tak rasa sangat...

Responden 2: $\quad$ Apa-apa kempen pun yang melibatkan partisipasi daripada masyarakat boleh menimbulkan semangat patriotik...bila di rumah macam saya dulu... aaa... bapa saya kerja dengan kerajaan... ibu pun bekerja dengan kerajaan ... jadi setiap kali Merdeka ... kita akan beli bendera-bendera Merdeka dan kereta juga di pasang dgn bendera... jadi... bendera besar... akan dipasak di tiang-tiang rumah la... dengan pintu rumah... jadi biasanya setiap benda tu... berlaku setiap tahun... ibu bapa terapkan kepada anak patriotik tu... bila balik rumah... tengok rumah mana yang banyak bendera tu... rumah kita... jadi jiranjiran pun suka... jadi saya rasa benda tu ... penerapan dari segi mak ayah kita la...

Namun begitu, terdapat informan yang merasakan bahawa sambutan masyarakat terhadap kempen Hari Kebangsaan sekarang ini kian pudar berbanding dahulu kerana kurang penghayatan erti sebenar Kemerdekaan.

Responden 5: $\quad$ Lagipun cuti hari Merdeka sekarang ni... tak ramai orang nak pergi ke tempat perarakan tu... sekarang ni cuti Merdeka... orang balik kampung... balik kampung nak duduk relaks je semua kan... maknanya dia lebih kepada benda-benda macam tu tau... bukan kata semangat macam dulu...aaa...mungkin sambutan sekadar sambutan tapi dia tak tahu penghayatan...

\section{Kempen sebagai Wahana Menyampaikan Mesej}

Selain menerusi pendidikan di sekolah, kempen Hari Kebangsaan dikenalpasti bertindak sebagai medium untuk menyampaikan mesej tentang patriotisme kepada belia seluruh Malaysia. Kempen Hari Kebangsaan adalah antara langkah dalam mendedahkan masyarakat pentingnya semangat patriotik dalam diri. Mesej yang diolah menerusi kempen mengumpulkan beberapa idea dari pemerintah dalam usaha menyampaikan maklumat kepada masyarakat secara tersirat dan tidak lansung. Mesej yang terkandung di dalam kempen ini mempunyai maksud tertentu dan melambangkan perkara yang ingin disampaikan. Apabila responden ditanya mengenai peranan kempen Hari Kebangsaan dalam menyampaikan mesej, mereka memberikan persepsi yang pelbagai.

Terdapat responden yang menyatakan bahawa mesej yang cuba disampaikan oleh kerajaan tentang Hari Kebangsaan itu sampai kepada masyarakat tapi dalam konteks pemahaman yang berbeza berdasarkan tafsiran individu tersebut.

Responden 6: $\quad$ Saya rasa sampai (mesej merdeka) ni tapi pemahaman dia lain... maksudnya ... dia happy-happy... dia rasa seronok... dia tak menghayati apa maksud disebalik merdeka tu... tapi dia seronok... sambutan tu dia rasa... tapi penghayatan tu lain... kalau kita selam hati dia... macam tu la... 
Ada informan yang menyatakan bahawa kempen Hari Kebangsaan yang dianjurkan menerusi media sosial kelihatan lebih meriah kerana faktor semasa. Perkembangan teknologi maklumat menjadikan media sosial sebagai medium yang sangat popular masa kini dalam penyebaran maklumat dengan pantas dan meluas.

Responden 1: $\quad \quad \quad$ Kalau saya masa kempen pasal kibar bendera ... di media sosial saya terasa betul sambutan yang hangat... budak2 sekarang itu pun dia upload di media sosial... jadi saya rasa... kalau di media sosial... nampak megah... saya rasa ... kita kena terima generasi... skrg ni betul2 cara dia... raikan (merdeka) tu lain...

Namun, terhadap informan yang menyatakan bahawa sambutan terhadap kempen Hari Kebangsaan kian pudar dan menyarankan agar bentuk kempen diubah mengikut kesesuaian semasa.

Responden 1: $\quad$ Mungkin cara kempen tu yang kena diubah... mungkin.... sebab kita melalui satu transition... dulu kempen memang nampak... mungkin sekarang tiba-tiba kerajaan... mungkin... ini pendapat... mungkin... tahun ni pulak... dengan huru hara pulak... maka kita kurang rasa... tapi kalau di media sosial... saya sangat merasai ...

Responden 4: $\quad$ Media sosial ni tak perlukan perutukan kewangan la... tak perlukan modal... modal takde... senang... bagi kita mungkin tak sampai kempen ni tapi bagi budak-budak.... mungkin dia faham merdeka ni benda lain...

\section{Perbincangan dan Kesimpulan}

Kempen penghayatan Hari Kebangsaan sememangnya penting dalam membentuk semangat patriotisme dalam kalangan masyarakat. Sungguhpun begitu, usaha menanam dan mencorakkan semangat patriotisme ini hanya dapat dijayakan sekiranya kempen dirancang dan dilaksanakan dengan betul agar ia mampu membangkitkan semangat patriotisme dalam diri masyarakat terhadap negara. Penyampaian mesej patriotisme menerusi kempen Hari Kebangsaan adalah sebahagian daripada usaha pihak pemerintah yang mahu menonjolkan kepentingan semangat pariotisme dalam diri masyarakat. Penekanan dalam bentuk kempen yang pelbagai dilakukan khusus untuk memberi penjelasan tentang nilai-nilai patriotik yang harus disemat dalam dada setiap masyarakat.

Kajian 'Kempen Penghayatan Bulan Kebangsaan Wahana Menyampaikan Mesej' ini berjaya merumuskan bahawa kempen penghayatan bulan Kebangsaan yang dijalankan oleh kerajaan telah memperlihatkan wujudnya mesej tentang patriotisme yang diwacanakan dengan kemas tetapi padat tentang pemujukan kerajaan kepada masyarakat untuk memupuk semangat patriotisme dalam diri masing-masing.

Jawapan informan amat membantu penyelidik untuk memahami bahawa kempen penghayatan bulan Kebangsaan anjuran kerajaan itu berjaya menyampaikan mesej dan seterusnya menerapkan kesedaran terhadap semangat patriotisme dalam kalangan belia. Menerusi kempen yang dianjurkan, masyarakat memahami mesej yang disampaikan oleh kerajaan dan menyokong penuh usaha yang dilakukan untuk memupuk semangat patriotisme. Penghasilan kempen yang betul, mampu membangkitkan semangat patriotisme dalam diri masyarakat terhadap negara.

Kempen penghayatan semangat patriotisme sempena Hari Kebangsaan dirasakan cukup penting kepada kerajaan sebagai penganjur kerana mekanisme inilah yang sebenarnya memiliki daya tarik atau fokus yang berkesan sekiranya kerajaan bercadang untuk menggunakan mekanisme tersebut bagi menyampaikan sesuatu mesej yang relevan kepada masyarakat. Justeru, tidak dinafikan bahawa agenda 
kerajaan itu telah berjaya mengeratkan lagi perpaduan antara kaum di Malaysia melalui semangat yang dicetuskan menerusi aktiviti kempen penghayatan Hari Kebangsaan yang pelbagai dan menarik.

Apa yang penting adalah usaha kerajaan melalui media massa dan media atas talian khususnya media sosial kini dilihat sebagai optimistik dan secara teknikalnya telah membantu menjayakan kempenkempen kesedaran Hari Kebangsaan yang dirancang dan dilaksanakan secara berterusan. Kempen yang berulang dan berterusan ini sekurang-kurangnya dapat membuka mata semua pihak tentang kemahuan kerajaan untuk mengekalkan semangat kebangsaan dan patriotisme sampai bila-bila. Kempen-kempen kesedaran untuk memupuk semangat mencintai negara ini pula sepatutnya merentas semua elemen budaya serta adat resam satu-satu kaum, bahasa, jantina, umur dan taraf pendidikan rakyat negara ini.

\section{Penghargaan}

Penyelidikan ini tidak mungkin dapat dilakukan tanpa sokongan daripada Universiti Malaysia Sabah (UMS) menerusi Skim Pensyarah Lantikan Baru (SPLB) dengan kod SLB0165-2018. Pengarang mengucapkan terima kasih kepada UMS untuk pembiayaan projek penyelidikan ini.

\section{Rujukan}

Abd Rahim Abd Rashid (2004). Patriotisme: Agenda Pembinaan Bangsa. Kuala Lumpur. Utusan Publications \& Distributors Sdn Bhd.

Ashiqin Rosselly (2018) Siapa Tak Kenal Tan Hong Ming? 15 Iklan Merdeka Yang Mampu Pupuk Semangat Cintakan Negara Dipetik daripada: https://says.com/my/seismik/iklan-merdeka-lama diakses pada 25 April 2019

Asmah Omar. (1986). Bahasa dan Alam Pemikiran Melayu. Kuala Lumpur. Dewan Bahasa dan Pustaka.

Billig, M. (1993). Studying Nationalism as an Everyday Ideology. Papers on Social Representation, $2(1), 40-43$

Billig, M. (1995). Banal Nationalism. London: SAGE Publications Ltd.

Baldi, P. \& Hasebrink, U. (2007) Broadcasters and Citizens in Europe: Trends in Media Accountability and Viewer Participation.UK: Intellect Books

Djajasudarma, F. (2012). Wacana dan Pragmatik. Bandung: PT. Refika Aditama.

Eko Prayitno Joko, Zaini Othman \& Saat Awg. Damit. (2016). Belia dan Kelansungan Hegemoni Barisan Nasional: Kajian Kes Pilihan Raya Umum 13 di Sabah. Jurnal Komunikasi Borneo (Edisi Khas Konvekesyen ke-18 UMS)

Fairclough, N. (1995). Critical Discourse Analysis: The Critical Study of Language. Harlow: Longman.

Faridah Ibrahim, Badrul Redzuan (2012). Membangun "Sinema Sikap": Memproblematik Hubungan Kekuasaan Melayu-Tionghua dalam Mukhsin. Jurnal Komunikasi, 27(2), 137-160

Hodge, R. \& G. Kress. (1988). Social Semiotics. Cambridge: Polity

Hodge, R. (1990) Literature as Discourse: Textual Strategies in English and History. Polity Press.

Idris Aman. (2000). Bahasa, Kuasa, dan Ideologi: Analisis Wacana Kritis Sebutan Baku Bahasa Melayu. AKADEMIKA, 56, 121-133.

Jewitt, C \& Oyama, R. (2001). Visual Meaning: A Social Semiotic Approach. London. SAGE Publications.

Kress, G. (2009) Critical Discourse Analysis dlm. Robert Kaplan, ed., Annual Review of Applied Linguistics, Vol. II.

Kress, G. (2010) Multimodality: A Social Semiotic Approach to Contemporary Communication. New York. Routledge.

Kress, G. (2012) Multimodal: Discourse Analysis. New York. Routledge.

Mohd. Foad Sakdan. (1997). Pengetahuan Asas Politik Malaysia. Kuala Lumpur. Dewan Bahasa dan Pustaka.

Moriarty, S. \& Duncan, T. (1990). How to Create and Deliver Winning Advertising Presentations. United States of America. NTC Business Books. 
Nayan Ahmad. (1984). Komunikasi Visual Kewartawanan Foto. Kuala Lumpur. Dewan Bahasa dan Pustaka.

Noor Mohamad Shakeel Hamid (2020). Hayati Semangat Sehati Sejiwa. Utusan Malaysia. Diakses pada 26 Ogos 2020.

Potter, J. \& Wetherell, M. (1992). Re-representing representations: discussion of Raty and Snellman. On-going production on Social Representations, 1, 15-20.

Ricoeur, P. (1986). Lectures on Ideology and Utopia. New York: Columbia University Press.

Shirato, T. \& Yell, S. (2000) Communication and Culture: An Introduction. Australia: Allen \& Unwin.

Sitinurbayu \& Badrul Redzuan. (2014). Implikasi Komunikatif Logo Hari Kemerdekaan: Sebuah Nota Penyelidikan. Jurnal Komunikasi, 30(1), 199-219

Syahruddin Hj. Awg. Ahmad. (2015). Aplikasi Model Analisis Proposisi Bingkai DPM dan Justifikasi Pendapat dalam Wacana di Laman Sosial dan Portal Berita. Jurnal Komunikasi Borneo, 2.

Tarigan Henry Guntur. 2009. Pengajaran Wacana. Bandung. Penerbit ANGKASA.

Van L., T. (2005) Introducing Social Semiotics. London. Routledge.

Wan Mohd Nor Wan Daud. (2015). Patriotisme dan Ketatanegaraan. Kuala Lumpur: Arial Communications Sdn Bhd

Yang, Y. (2016). A Social Semiotic Approach to Multimodal Discourse of the Badge of Xi'an Jiaotong University. Theory and Practice in Language Studies, 6(8), 1596-1601.

Zainal Abidin Abdul Wahid et al. (1996). Malaysia: Warisan dan Perkembangan. Kuala Lumpur. Dewan Bahasa dan Pustaka. 